\title{
Physical Activity of Blind Children in Terms of Parenting
}

\author{
Akhmad Olih Solihin ${ }^{1,2, *}$ \\ ${ }^{1}$ Department of Physical Education, Health and Recreation \\ ${ }^{2}$ Doctor's Program in Sports Education, The School of \\ Postgraduate Studies \\ ${ }^{1}$ STKIP Pasundan, ${ }^{2}$ Universitas Pendidikan Indonesia \\ ${ }^{1}$ Cimahi, ${ }^{2}$ Bandung, Indonesia \\ *yoyoolih@gmail.com
}

\author{
Yudha M. Saputra, Berliana Berliana \\ Faculty of Sports and Health Education \\ Universitas Pendidikan Indonesia \\ Bandung, Indonesia
}

\author{
Zaenal Alimin \\ Faculty of Science Education \\ Universitas Pendidikan Indonesia \\ Bandung, Indonesia
}

\begin{abstract}
This study departs from the idea that parenting is fundamental to the survival of a child, each parenting style that is carried out by parents will describe the child's behavior, both physically and mentally. Compared to other children, those who have barriers to vision have additional challenges to being physically active. For this reason, it is very important that physical activity interventions are guided by parents. This study aims to provide an overview of how the physical activity of blind children in terms of parenting parents. The method used in this study is a qualitative method using observation and interviews. Participants used by SLB A Citeureup Cimahi students by using snowball sampling technique. The results of research on the physical activity of children with visual impairments are very concerning, let alone for sports activities, their daily physical activity is not good. The findings of this study that actually blind students from small are not cared for by biological parents, but by parents of guardians.
\end{abstract}

\section{Keywords—physical activity; blindness; parenting}

\section{INTRODUCTION}

Persons with disabilities are often socially isolated and face discrimination in access to health, education, employment and other services. Although conceptually disability needs to get the attention and assistance of all of us who are still normal, in reality many people have different perspectives in addressing the current disability. Coupled with a low economic presence, increasingly isolated and marginalized in every community activity. Findings that point to over $90 \%$ of persons with blindness or partial sight in low-income countries where most of them are considerably reduced and excluded from community-based activities [1]. Public attitudes have an impact on material and non-material aspects of the standard of living of all people, and people with disabilities in particular, and most people who continue to be negative towards people with disabilities and attitudes are supported by a lack of understanding of disability.
Similar to most people in general, people with disabilities also need physical activity. Physical activity (PA) has many benefits for both mental and physical health. Cardiovascular diseases, diabetes, obesity, cancers and depression are some of the health conditions that can either be prevented or treated by PA $[2,3]$.

People with visual impairment with visual limitations have difficulty getting experience in physical activity, compared with those who experience hearing loss and some physical disorders. Visually impaired people are less active in physical activity. In a sample of children and adolescents aged 6-20 years old reported that people with visual impairment (VI) are more inactive compared to individuals with hearing loss and some types of physical impairment [2,4]. Major findings suggest that, in comparison to peers without disabilities, those with visual impairments tend to perform significantly greater delays in fundamental motor skills (FMS) [5]. Children who are blind are at greater risk of falling due to poor balancing skills [6]. Furthermore, Visual loss, besides causing changes in posture control, leads to increased social dependence, limitation in the performance of daily activities, and increases the chances of falling [7].

Special Schools (SLB) are special schools for school-age children who have "special needs". SLB educational institutions are educational institutions that aim to help students with physical or mental, behavioral and social disorders in order to be able to develop their attitudes, knowledge and motor skills as individuals and community members in making reciprocal relationships with the surrounding social, cultural and natural environment and can develop skills in the world of work or follow further education.

From the problems that exist, the SLB must have a special physical education teacher who is supported by the involvement of parents so that the blind children can do physical activities. Lack of encouragement from parents 
because they feel ashamed of having children with limited vision, and lack of professional training for teachers on how to apply forms of physical activity for the blind. Several factors have been identified that limit physical activity participation for those with visual impairments, such as a lack of knowledge of opportunities [5,8]. Parental encouragement [5,9]. Professional training of teachers $[5,10]$.

This study aims to provide an overview of how the physical activity of blind children in terms of parenting parents.

\section{METHOD}

The method used in this study is a qualitative method using observation, interview techniques. Participants used by SLB A Citeureup students in Cimahi City by using snowball sampling.

\section{RESUlt AND DisCUSSION}

Movement, that is physical activity, is fundamental for us humans [11], because by moving humans can maintain their lives. Being able to move without obstacles is something that is highly expected for everyone, but not a few people who move have limited, this is caused by the inability of the sense of sight in carrying out its functions. Involvement in physical activity (PA) provides multiple benefits, not only for individuals with visual impairments (VI), but for the entire family. Recent evidence suggests that a child's level of disability (e.g., level of vision) influences her or his level of PA participation. Moreover, children with VI are impacted by the availability (or lack) of PA opportunities [8,12].

Loss or lack of vision limits the child's ability to know where he is, how to move from one place to another, imitate, interact socially, and understand what causes things to happen. Even daily activities such as mopping, sweeping, cleaning their beds are difficult, so they don't want to do it. Coupled with the attitude of parents who do not try to teach the activity. This is because after asking all blind children that the blind students from small children are not cared for by biological parents, but by the guardian's parents.

But when they settled in the dormitory their habits changed, because they had to be able to live independently like one of the blind children totally blind before he entered the dorm they never did physical activities such as mopping, sweeping and cleaning the bed, but after they entered the dormitory activity they can do it guided by caregivers in the dormitory.

Therefore, children with visual impairments are lacking in physical activity. From the results of the first interview with blind students, the authors got several points on how the physical activities of the blind children are: 1) Starting they sleep late, so they sleep less and the results when they go to school they are not concentrated and sleepy; 2) Their activities in the dormitory are spent a lot with religion this is because there are no board administrators who know how to exercise well and correctly; 3) Physical activity activities in the form of sports they usually do running, push ups and sit ups; 4) Break time at school they spend more on snacks and chatting with friends; 5) Physical activity activities in the form of sports physical education and health only once a week in school. Swimming once a month.
From the results of the second interview with $\mathrm{Mr}$, Aep, the author received several points for doing daily physical activities of blind children: 1) People who sleep are obliged to hit before 9:00 p.m. However, the bedroom in the boardroom is not as usual; 2) Their daily activities in the dormitory are more in the religious field; 3 ) Physical activity activities in the form of push ups are carried out as lessons for students and students who speak the rules in the dormitory; 4) Physical activity activities are physical physical education and health is only carried out at school.

The results of the third interview with Mrs. Hesbayanti, the author got several points of reinforcement about how the physical activity of blind children: 1) Sleep them late at 21.00; 2) Children with visual impairments only do light physical daily activities, such as cleaning the bed and washing. Whereas physical activity in the form of sports or those who are heavy in the dormitory have never been, and if they do, someone must invite.

From the three interviews above, it can be concluded that there are irregularities between physical activity in the form of sports carried out by students in the form of running, push ups and sit ups. When linked to the results of the interview, the physical activity in the form of push ups is only done as a sanction if they violate the rules in the dormitory. And they tend to do physical activity in the form of sports only because of solicitation, when no one invites them not to exercise, that is a statement from the interview with Mrs. Hesbayanti.

Actually when learning physical education is done well at school, it will foster good social relationships among their peers. Besides that, it will also be able to build students' motivation to exercise outside of learning hours. The preparation of sports and health physical education learning program for blind students to be totally blind, must be able to adjust to the type and characteristics of blind people totally blind, physical education program must also be able to help and correct abnormalities in blind students for totally blind. And must also be able to develop and enhance the individual's physical abilities, with the suitability of the program for children with visual impairments to avoid the occurrence of boredom and the most important thing is to create a great motivation to exercise, especially those with a blind blindness. Allen found support for the construct validity of all three social goals with adolescents involved in sport. Furthermore, she found that all three social goals had moderate positive relationships with interest in sport while social affiliation and social recognition goals had small negative relationships with boredom [13].

When the physical activity program in the form of physical education in accordance with the needs of blind students, especially those who are totally blind, directly not only physical benefits are obtained but will arise happiness in the child and the body feels more energized. Reported that both social affiliation and recognition goals within Allen's framework were positively related to eudemonia (i.e. feeling energized and fully alive) in a sample of adolescent footballers (i.e. soccer players) in the UK [13]. 


\section{CONCLUSION}

The results of research on the physical activity of children with visual impairments are very concerning, let alone for sports activities, their daily physical activity is not good. The findings of this study that actually blind students from small are not cared for by biological parents, but by parents of guardians.

\section{ACKNOWLEDGMENT}

The author thanks Prof. Dr. Yudha M. Saputra, M. Pd, Dr. Berliana, M. Pd, and Dr. Zaenal Alimin, M. Ed as mentor in writing this article. Then the author expressed his love also to the ICSSHPE 2018 committee who gave the author the opportunity to publish this article.

\section{REFERENCES}

[1] P. Ajuwon and R. Bieber, "Vision Impairment and Quality of Life," Int. Public Heal. J., vol. 6, no. 4, p. 341, 2014.

[2] R.B.P. Da Silva, A.C. Marques and F.F. Reichert, "Objectively measured physical activity in brazilians with visual impairment: Description and associated factors," Disabil. Rehabil., vol. 40, no. 18, pp. 2131-2137, 2017.

[3] A.E. Bauman, "Updating the evidence that physical activity is good for health: an epidemiological review 2000-2003," J. Sci. Med. Sport, vol. 7, no. 1 , pp. 6-19, 2004
[4] P.E. Longmuir and O. Bar-Or, "Factors influencing the physical activity levels of youths with physical and sensory disabilities," Adapt. Phys. Act. Q., vol. 17, no. 1, pp. 40-53, 2000.

[5] J. a. Haegele, A. Brian, and J. Goodway, "Fundamental motor skills and school-aged individuals with visual impairments: A review," Rev. J. Autism Dev. Disord., vol. 2, no. 3, pp. 320-327, 2015.

[6] T. Morelli, E. Folmer, J.T. Foley and L. Lieberman, "Improving the lives of youth with visual impairments through exergames," Insight Res. Pract. Vis. Impair. Blind., vol. 4, no. 4, pp. 160-170, 2011.

[7] A.V. Soares, C.S.R. de Oliveira, R.J. Knabben, S.C. Domenech and N G. B. Junior, "Postural control in blind subjects Análise do controle postural em deficientes visuais," Einstein, vol. 9, no. 4 Pt 1, pp. 470476, 2011.

[8] M.E. Stuart, L. Lieberman and K.E. Hand, "Beliefs About Physical Activity Among Children Who Are Visually Impaired and Their Parents," JVIB, vol. 100, no. 4, 2006.

[9] S. Ward, C. Farnsworth, M. Babkes-Stellino, and J. Perrett, "Parental influence and the attraction to physical activity for youth who are visually impaired at a residential-day school,” J. Vis. Impair. Blind., vol. 105, no. 8, pp. 493-498, 2011.

[10] L. Lieberman, C. Houston-Wilson, and F.M. Kozub, "Overcoming the Barriers to Including Students with Visual Impairments and DeafBlindness in Physical Education.," Adapt. Phys. Act. Q., vol. 19, no. 3, pp. 364-377, 2002.

[11] M. Hagströmer and E. Franzén, "The importance of physical activity and health for physical therapy," Phys. Ther. Rev., vol. 22, no. 3-4, pp. 116 123, 2017.

[12] L. Columna, S.R. Dillon, M. Dolphin, D.A. Streete, S.R. Hodge, B. Myers and K.S. Heffernan, "Physical activity participation among families of children with visual impairments and blindness," Disability and rehabilitation, vol. 41, no. 3, pp. 357-365.

[13] T.L. Wallhead, A.C. Garn and C. Vidoni, "Effect of a sport education program on motivation for physical education and leisure-time physical activity,” Res. Q. Exerc. Sport, vol. 85, no. 4, pp. 478-487, 2014. 